The significance of motivation in student-centred learning: a reflective case study

\title{
Introduction
}

Currently, student-centred learning is part of the rhetoric in higher-education pedagogy. The assumption that student-centred learning should be promoted is not being debated here. Rather, the intention is to examine what student-centred learning implies for the construct of motivation which, of itself, is an equally demanding idea in higher education. The central idea of studentcentred learning is that students determine in large measure what, how and when to think, rather than rely exclusively on tutors (Gibbs, 1992). Student-centred learning contrasts with tutorcentred learning, vividly described by Hogan(1996):

I was struck by the irony that I did an enormous amount of reading and thinking about education in order to prepare my lectures, plan effective workshops and select readings and texts for my students, while the students did relatively little. I was the most active learner in my class - because I had total responsibility for what was learned and how it was presented for consumption ( $p$. 79).

Student-centred learning seeks to provide the focus and structure that lets students take responsibility for the cognitive and metacognitive aspects of their learning (Bereiter \& Scardamalia, 1993; Elen et al, 2007). Moreover, student-centred learners are assumed to regulate both their learning and their motivation synergistically (Boekaerts, 1999; 2003) to accomplish curricular goals (Pintrich \& Schunk, 2002). While motivation is both a precondition for, and in itself a subject of, self-regulation, the purpose of this article is to give conceptual consideration only to the component of motivation because of its centrality in explaining learning and achievement behaviour (Spinath, 2005).

Motivation is a psychological construct and is not synonymous with the actual behaviours involved in a particular activity (Hufton et al, 2002). While historically prevalent views assume that motivation is an integral component of all learning (Harlen \& Deacon Crick, 2002; Torrance \& Coultas, 2004), there is a growing body of literature to suggest that what motivates some students may alienate others (Harlen \& Deacon Crick, 2003). This article seeks to draw 


\section{The significance of motivation in student-centred learning: a reflective case study}

attention to the significance of such psychological literature across the stages of the teachinglearning process, through reflecting on data derived from a specific case.

\section{The Case}

Exemplifications of student-centred learning essentially orchestrate events such that students influence/improve/alter their own cognitive processing (Perrenoud, 1998). The case that is being reflected on here was one such attempt: students (final year teacher-education undergraduates in a Scottish university) were exposed to a carefully planned and integrated sequence of activities in a module on Learning Theory in which socially constructed knowledge was represented (Hickey \& McCaslin, 2001). The rationale for this, together with the need for prospective professional teachers to construct their own understandings of the relevant research literature as a means of being able to evaluate their own learning about, and practical experiences of, teaching (James \& Pedder, 2006; Leinhardt et al, 1995) was explicit both in the module documentation and in its pedagogy. This included an explicit list of prescribed reading from books and periodicals; suggestions for how students might use the substance of such reading to engage in higher order thinking both individually and collectively; a timetabled programme of class meetings involving differential participatory roles; and a series of openended tasks/investigations for which students were accountable from initial conception to completion. All data were gathered by academics and research assistants in authentic pedagogical contexts and the findings from focus group interviews, content analysis of written output and observation of student behaviour in different contexts and tasks are reported elsewhere (Maclellan \& Soden, 2004; Soden \& Maclellan, 2005). The phenomena of interest in the case were student perceptions of how learning is best supported. 
The significance of motivation in student-centred learning: a reflective case study

\section{Methodology}

\section{$\underline{\text { Rationale }}$}

What is the focus of this article is theoretical reflection on the main axes of difference in student's perceptions, since the revisiting of previously collected material can be fruitful both in terms of substantive conceptual refinement and the development of methodological tools. This focus was triggered by the preponderance of data items from interviews and written output which pointed to student conceptions of the episodes in the cycle of learning. Illustrations of these data items can be found in the appendix. In particular the data items suggested that, typically, students were reluctant to embrace practices associated with student-centred learning. Concerns about this overall finding gave rise to the possibility that students were not motivated to fully engage with their learning.

Reflecting on the significance of motivation in the teaching-learning cycle is appropriately served by case-study (Stake, 2003). Of Stake's three types of case-study, the instrumental case study is closest to this author's aim: to provide insight into an issue rather than the details of the case being of primary interest (which they would be in an intrinsic case-study). There is, here, a deliberate attempt to understand a specific case through interpreting its systematically gathered details within a body of extensive propositional knowledge; which in this study is the literature on socio-cognitive models of motivation. In other words, if motivation is both pervasive and pivotal in human behaviour (Pintrich \& Schunk, 2002), it is clearly relevant to pedagogical practice. The aim of this reflective case-study is to derive a number of fuzzy propositions (Bassey, 1999) from the literature that seem to be implicated in the cyclical nature of teachinglearning episodes. Fuzziness is considered to be a valuable mode of formulation in any evidence-based proposition for future action (Hammersley, 2001) given that completeness, certainty and precision are unattainable in the social world. 


\title{
The significance of motivation in student-centred learning: a reflective case study
}

\begin{abstract}
$\underline{\text { Method }}$
The method was in two stages. The first was the creation of an analytical framework. The process of engagement in formal education typically operates in a cycle of episodes: a learning task (or series of tasks) is determined; the student attends to the task (usually over continuing time); and the completion of the task is marked by some sort of feedback about student performance. The episodes presuppose interdependence in the cycle. For example without some notion of how the task is or was being carried out, feedback is a meaningless idea. Equally, continuation or completion of a task necessarily implies that at some point the task was determined. Finally, (rational) determinations of tasks imply a necessary relationship to previous learning. The episodes of Task Determination, Task Continuation and Task Completion provided the structural framework within which data were categorised. From a very large bank of recording units previously derived according to Tesch (1990), approximately 200 meaning units - segments of text that are comprehensible by themselves and contain one idea or piece of information- were extracted by coders who assigned each to one of the episodes in the cycle. The selection of the units was essentially random but with the aim of achieving evenly sized quotas for each category, resulting in 65-70 recording units being assigned to each. The creation of an analytical structure that is pedagogically derived allows the implications for practice to be easily obvious.
\end{abstract}

The second stage was to subject the units in the episodes to theoretical analysis, recognising that the episodes themselves permit variation in interpretation depending on whether a studentcentred or tutor-centred learning is the pedagogical driver (Vermunt \& Verloop, 1999). Episodes were explored in terms of motivational constructs. While motivation is often referred to in the educational literature as a unidimensional phenomenon, this is misleading since both its dynamic variation and its context-dependency has generated a large number of constructs that may facilitate or constrain student learning. Key constructs include goal orientation, volition, interest and attributions. In this study the four constructs are used to explain the typical and 


\section{The significance of motivation in student-centred learning: a reflective case study}

minority student perceptions of the episodes in the learning cycle, thereby permitting a more detailed and integrated argumentation on the role of motivation than pedagogical researchers have hitherto presented.

\section{$\underline{\text { Task Determination }}$}

Data item reflecting minority view of task determination. The booklet that goes with the module is good because all the tasks are there for all of us to see. But it's up to us to decide which are the important ones in our own study groups. So the first thing we have to do when we are deciding on which task to do is to talk about what we think the task really means. Sometimes that can take ages but then we can always run it past the tutor to see if she thinks we're going about it the right way. But that's why it's important to try out the task on your own, first of all, 'cause then you kind of know what reading you should do or what questions to ask. I don't want to let the others in my group down so I always do my own preparation first.

Data item reflecting typical view of task determination

I don't like it when I'm confused about what to do. I want to know exactly what I'm supposed to be doing. Tutors should tell you, straight. They are the ones who know what is to be learned. So if they want us to discuss questions, it's their job to bring questions, not the students'. When I have a question to ask I want to be able to ask the tutor who can then tell me the right answer. I don't think that kind of question is for discussion by the class. How could the others help me?

The minority view was that students had a role in shaping the task whilst the typical view was that task determination was exclusively the tutors' prerogative. In the context of formal higher education, students follow courses that have been planned and specified in advance so that they can be coherent, developmental and at an appropriate level of cognitive demand. In pedagogical terms this is typically translated into tutor determination of task. Tutors thus have learning intentions and achievement-directed behaviour in mind when determining tasks. But students also have reasons for engaging in such tasks. These goal orientations are important because they underpin students' definitions of their own competence (Pintrich \& Schunk, 2002). Simply put, these orientations are in terms of the mastery or performance goals.

Students with mastery goals define competence in terms of self-defined improvement. In so doing, they variously experience enhanced interest in learning, more positive attitudes toward learning, errors as informational, failure attributed to lack of effort (rather than lack of ability), high levels of academic engagement and effort, perseverance in the face of challenges, more risk-taking, and focussed help-seeking (Pintrich, 2003). With performance goals, on the other 


\section{The significance of motivation in student-centred learning: a reflective case study}

hand, students are more likely to engage in self-handicapping behaviours, such as cheating, avoiding help when they need it, and withdrawing effort. They may view errors as indicating a lack of ability, experience high levels of anxiety, exert less effort, place less value on tasks, give up in the face of difficulty, and ultimately demonstrate lower levels of achievement (Pintrich, 2003).

However, it cannot be assumed that students always have a mastery orientation, nor indeed should they (Elliot et al, 2005). Basic psychological needs of autonomy, competence and social relatedness (Krapp, 2003) may result in a perfectly proper preference for performance goals and indeed, at any one time both mastery and performance goals can co-exist. It is not therefore the intention to characterise performance goals in exclusively negative terms. While the evidence on goal orientation is much more convoluted and contested than the depiction here suggests, the general desirability of mastery goal orientations and the maladaptive possibilities arising form performance-avoid goal orientations draw attention to their pivotal role in establishing the direction of subsequent learning.

Fuzzy Proposition $1 \quad$ Because of the reasonable possibility that students' and tutors' intentions for learning may not be congruent (Boekaerts \& Minnaert, 1999), it seems important that both tutor and student to be explicit about their perspective goal orientations, possibly to the point of establishing multiple and even conflicting goals for learning (Oettingen et al, 2000). Without such discourse students, as was typically reflected in this case, will continue to believe that they have no role in task determination. Explicit and systematic consideration of taskdetermination might help students to identify both proximal (task-specific, target) and distal (high-level purpose) goals without which student-centred learning can be no more than a meaningless strapline. Although goal orientation is important for initial student 'ownership' of learning, it is of itself insufficient. 


\title{
The significance of motivation in student-centred learning: a reflective case study
}

\author{
$\underline{\text { Task Continuation }}$
}

Data item reflecting minority view of task continuation

To begin with, I wondered why we were to do read some of these journal articles. They're all about theories and my job as a teacher is practical. But because she said that in the assessment we had to show that we had understood some of the articles, I kept trying. But see now, it's all coming together. This stuff does tie up with what we do in school. When I'm out on placement and something crops up, I can't wait to look in the journals to see if somebody's written about that. And there's loads there

Data item reflecting typical view of task continuation All of the modules we do are supposed to help us be good teachers. Some of the things in the module about how children learn are quite interesting but the schools we work in have their own policies for what's to happen so that's all I really need to know to do my job. I mean in my last placement the policy was to give lots of praise and rewards so there's no point in me knowing about other theories. The stuff we're supposed to do between classes need us to get together in groups. But most people don't see the point of them and they don't bother to do them. And I don't like speaking out in the group. And thinking of answers to these questions needs a lot of time and I find it better to use the time to swot up the lecture notes.

The minority view was that learning was an open-ended activity with intrinsic momentum, whilst the typical view was that learning was a set of arbitrary tasks to be endured or, better still, avoided. Once the task has been determined, execution of the learning process is now necessary. Within a student-centred approach, maintaining focus and effort in the achievement of goals despite potential distractions and competing goals is necessary. One condition which engenders student volition (Corno, 1994) is interest; a construct that is more involved than lay usage might suggest. The appeal of an activity (Krapp \& Lewalter, 2001), rather than the individual's personal preference for the activity (Mitchell, 1993), is known as situational interest. Situational interest includes dimensions of novelty, challenge, intentions to engage with the task, the attentional demands of the task, and the instant enjoyment engendered by the task (Chen et al, 2001). As such, it may last for varying amounts of time but is of critical importance in formal education (Hidi \& Harackiewicz, 2000) since it is situational interest that provides the basis for increasing and elaborating domain knowledge.

Situational interest that triggers engagement with particular domain content may lead to personal interest which is the constant and consistent interaction with the domain. The development of personal interest is in part maintained by the fulfilment of the three essential 


\section{The significance of motivation in student-centred learning: a reflective case study}

needs, mentioned above, that are important for psychological well-being and growth: competence (experiences of high efficaciousness), autonomy (experiences of independence and self-determination), and relatedness (experiences of being connected to, and accepted by, others) (Krapp, 2005). It is personal interest that allows recognition of meaning in a learning task, leads to the use of deeper cognitive strategies (and thus to meaningful learning behaviours), is associated with increased attention and persistence, promotes long-term storage of knowledge, and provides motivation for continued engagement in learning (Chen et al, 2001). These features of personal interest depend on domain knowledge. Thus it is domain knowledge which is the essence of the interest; which might seem counter-intuitive in everyday parlance where interest is characterised as an affective quality of engagement. Domain knowledge must ultimately satisfy one or more of the three essential psychological needs for it to become intrinsically motivating to persist with some specific learning (Krapp, 2005).

However, while interest is desirable, unbridled interest can make it harder to be adaptive so students need to articulate interest with overall goals, particularly when goal orientations are clearly differentiated across time (Heckhausen \& Farruggia, 2003). Student volition can be supported by adaptive help-seeking (Newman, 1994). In other words, to effect change, students may well need the assistance of more knowledgeable others. That people avoid seeking help even when to do so might solve difficulty (Butler, 1998a), foregrounds the complexity of adaptive help-seeking. It has been suggested that students are reluctant to seek help either because they perceive help-seeking to be inconsistent with personal needs for autonomy or a (threatening) sign of incompetence (Butler, 1998a). Newman (1998), however, found that the help most frequently sought was process-related information: information that would enable them to build on what they themselves were trying to work out, rather than seeking confirmation of previous work or correct answers. Newman further found that students with strong performance goals, in contexts that emphasised performance goals, were particularly reluctant to seek help while those working in a mastery oriented context were more willing to 


\section{The significance of motivation in student-centred learning: a reflective case study}

seek help, suggesting that contextual variables may well be powerful. For students to retain control of their learning and advance it through help-seeking, they need to be willing to acknowledge personal difficulty and desire interaction with more knowledgeable others. Further they need goals and beliefs that are associated with personal agency and control, a desire for challenge and tolerance for task difficulty (Newman, 2002).

Fuzzy Proposition 2 Task-continuation will be ideally maintained when students experience the activity's domain knowledge to be psychologically satisfying. Situational (perceived relevance) and personal (intrinsic importance) interest articulate with aspects of taskdetermination in non-trivial ways and to support student-centred learning this interest must be managed by both tutor and student, interactively. One mechanism to be invoked in such management is adaptive help-seeking. The judicious balance of volition, interest and helpseeking needed to continue with a task is an aspect of pedagogical practice that is worthy of further study and elaboration.

\section{$\underline{\text { Task Completion }}$}

Data item reflecting minority view of task completion.

I usually take 3 weeks to write my assignment but this time it's taken 3 days. I think it's because I got to understand the stuff so well during the module: I can now see how constructivism helps to get the stuff sorted in my head. We did all these hard tasks ourselves and then had a chance to talk about and hear about what others had done at tutorials. And you never said it was good-you just asked us questions.

Data item reflecting typical view of task completion.

At the end of the module I need to be able to pass the assessment. I can do this if the tutor breaks down the assignment into smaller learning outcomes. But I can't look at the assignment and say, "Yes, this is how I'm going to carry it out". I get really confused when one tutor says we should think about suchand-such but another tutor says something different. The assessment shouldn't be so challenging that we do not clearly understand what we are doing. It is not the tutor's job to give us difficult tasks.

The minority view was that task completion was an opportunity to reflect on progress and achievement whilst the typical view was that task completion was a time-ordered, evaluative marker, which was largely in the gift of the tutor. Such different views will have varying effects on subsequent motivation and achievement (Struthers et al, 1996; Struyven et al, 2003) since the 


\section{The significance of motivation in student-centred learning: a reflective case study}

interpretation of events is mediated by the attributions people make of the locus of control, stability, and controllability of the tasks to be completed (Weiner, 1979; 1985). While the full array of attributional categories cannot be examined in this limited secondary analysis, their pedagogical implications merit brief attention.

The evidence (Pintrich \& Schunk, 2002) suggests that students drawing from an internal locus of control, viewing 'success' and 'failure' as contingent on their own behaviour, have greater potential for high-achievement than do students who deny the importance of their own agency and attribute successful task-completion to external factors that they may feel are unchangeable. Such students may not actually complete tasks or complete tasks with low expectations of success and, having experienced a continuing or recent cycle of failure, conclude that continued engagement serves only to confirm their failure. Regrettable as this may be, it is a difficult cycle to penetrate when learners try hard and fail or when tutors' own efficacy is not strong in respect of influencing learners (Dweck, 2000). Strengthening the internal locus of control is therefore a pedagogical concern to change views of intelligence from a fixed and unchangeable trait to a malleable, improvable skill (Dweck, 2000), and to improve self-efficacy (Bandura, 1997).

Experiencing reward through effort is one way of improving efficacy. Such mastery experiences, however, must not be at the 'cost' of carrying out a task that is insufficiently challenging (Dweck, 2000), which would attenuate the need to be effortful. Another way of improving efficacy is encouragement but while the tutor's verbal persuasion may convince a doubting student to persist, the tutor is not being supportive if the persuasion is not calibrated to realistic levels of accomplishment in terms of task component capabilities. It is in this way that effusive, non task-specific praise is meaningless, and misleading when it causes students to overestimate their abilities. Although it might appear to be common sense that tutors should say what they can to reassure students who appraise themselves negatively, blunderbuss reassurance may be counter-productive. Butler (1987; 1988b; Butler \& Neuman, 1995) found that ego- 


\section{The significance of motivation in student-centred learning: a reflective case study}

involving feedback was much less likely to encourage students to engage with the essentials of the task, underlining later work (Struyven et al, 2003) that anxious students benefit from their attention being focused on the assessment task demands, rather than their emotional preoccupations which may actually attenuate perseverance. The potential power of students' own attributions suggests that there be greater attention afforded to the students' views on the tasks to be done and on the judgements of their achievements. It may also be appropriate to invoke attribution training whilst recognising that we have limited access to our own mental processes (Nisbett \& Wilson, 1977) and also recognising the pervasiveness of the self-serving attributional bias (Mezulis et al, 2004) in which people make more internal, stable, and global attributions for positive events than for negative events.

Fuzzy Proposition 3 By requiring students to be much more pro-active in taskdetermination, continuation and completion, they would have opportunity to take ownership of the criteria for assessment; to have increased responsibility for their learning; to become selfmonitoring and independent; to realise that their judgements are respected; and to encourage critical self-reflection on learning behaviours (Topping, 2003). However, such practices are emotionally challenging (Boud, 1995) and their integrity is easily compromised by reliability and validity issues (Birenbaum, 1996). These difficulties may cement emotionally immature attitudes (such as low frustration tolerance or tutor dependence) towards learning, perpetuate expectations of low or minimal standards and privilege the public monitoring of academic performance (with possibly humiliating connotations) (Brophy, 1999). Clearer understanding of the literature on socio-cognitive understandings of motivation may be helpful in promoting student-centred pedagogy.

\section{Conclusion}

An earlier study had shown that, whilst a minority expressed interest in an equitable balance between tutors' and students' endeavours, the dominant view was that student learning was 


\section{The significance of motivation in student-centred learning: a reflective case study}

largely the tutor's responsibility. Furthermore, within the content of what tutors were to be responsible for, the overriding wish was for easily digestible, immediately obvious 'theoretical' views that confirmed extant understandings (however, primitive or prejudiced these might appear to be in the light of evidence for socio-cognitive and socio cultural explanations). This triggered a sample of the initial study's recording units being theoretically analysed using sociocognitive motivational constructs. Three fuzzy propositions emerged from consideration of the literature. Within the cycle of teaching-learning both tutor and student need to be explicit about their perspective goal orientations, even if this means including multiple and possibly conflicting goals for learning. Student interest is critical to the continuation and completion of learning tasks but needs to be managed through appropriate help-seeking. Finally, the importance of students taking responsibility for their own learning can only find manifestation in systemic arrangements that appropriate new modes of assessment and that recognise the emotional and affective underpinnings of learning.

What is being implied through the motivational literature considered here is that tutor activity of clarifying the subject matter, offering examples, or suggesting arguments for or against a point of view may minimise the students' need to think. If students view the tutor's cognition as essential for the development of their own skills and knowledge, they are positioned in a teacher-centred set of expectations and practices making them tutor-dependent. Equally little engagement by the tutor, leaving students to determine both what and how to learn without any criteria to judge their progress, is unsatisfactory, inefficient and makes a nonsense of formal, higher education as a planned and designed system. A judicious balance of students engaging in tasks through the stimulation of tutors (who perhaps ask detailed questions, have students present arguments, require students to analyse the cause of their problems) requires considerable sensitivity, strength of conviction to allow students to regulate their motivation, and skills of negotiation since misperceptions may lead to scaffolding mismatch in instruction and negative perceptions of the interacting partners in certain learning situations. While much of what has 


\section{The significance of motivation in student-centred learning: a reflective case study}

been proposed here remains to be empirically substantiated within the constraints and affordances of present-day higher education, the higher-level cognitive competencies that are implied by the term, student-centred learning, underline the importance of course design and delivery being explicitly underpinned by the motivational principles reviewed in this case study, if improved levels of autonomous student behaviour are to be promoted.

\section{References}

Bandura, A. (1997) Self-Efficacy: the exercise of control (New York, W. H. Freeman \& Company).

Bassey, M. (1999) Case Study Research in Educational Settings (Buckingham, UK, The Open University Press).

Bereiter, C., \& Scardamalia, M. (1993). Surpassing ourselves: An inquiry into the nature and implications of expertise (Chicago, Open Court).

Birenbaum, M. (1996). Assessment 2000: Towards a pluralistic approach to assessment, in: M. Birenbaum \& F.J.R.C. Dochy (Eds.), Alternatives in Assessment of Achievements, Learning Processes and Prior Knowledge (Boston, Kluwer), 3-30

Boekaerts, M. (1999) Self-regulated learning: where we are today, International Journal of Educational Research, 31(6) 445-57.

Boekaerts, M. \& Minnaert, A. (1999). Self-regulation with respect to informal learning, International Journal of Educational Research, 31(6) 533-44.

Boekaerts, M. (2003) Towards a model that integrates motivation, affect and learning. Development and Motivation, BJEP Monograph Series II, 2, 173-89.

Boud, D. (1995) Enhancing Learning through Self Assessment (London, Kogan Page). 


\section{The significance of motivation in student-centred learning: a reflective case study}

Brophy, J. (1999) Research on motivation in education: past, present and future, in: T. Urdan (Ed.) Advances in Motivation and Achievement, Volume 11, The Role of Context (Greenwich, CT, JAI Press), 1-44.

Brophy, J. (2002). Social Constructivist Teaching: Affordances and Constraints (Oxford, Elsevier Science Ltd)

Butler, R. (1987) Task-involving and ego-involving properties of evaluation: Effects of different feedback conditions on motivational perceptions, interest and performance, Journal of Educational Psychology, 79 (4), 474-482.

Butler, R. (1998a) Determinants of help-seeking: relations between perceived reasons for classroom help-avoidance and help-seeking behaviors in an experimental context, Journal of Educational Psychology, 90 (4), 630-43.

Butler, R. (1988b) Enhancing and undermining intrinsic motivation; the effects of task involving and ego-involving evaluation on interest and performance, British Journal of Educational Psychology, 58, 1-14.

Butler, R. \& Neuman, O. (1995) Effects of task and ego-achievement goals on help-seeking behaviours and attitudes, Journal of Educational Psychology, 87 (2), 261-271.

Chen, A., Darst, P. \& Pangrazi, R. (2001) An examination of situational interest and its sources, British Journal of Educational Psychology, 71, 383-400.

Corno, L. (1994). Student volition and education: outcomes, influences, and practices, in: D. Schunk, \& B. Zimmerman (Eds.) Self-Regulation of Learning and Performance (Hillsdale, NJ: Erlbaum), 229-51.

Dweck, C. (2000) Self-Theories (London, Psychology Press). 


\section{The significance of motivation in student-centred learning: a reflective case study}

Elen, J., Clarebout, G., Léonard, R. \& Lowyck, J. (2007) Student-centred and teacher-centred learning environments: what students think, Teaching in Higher Education, 12 (1), 105-17.

Elliot, A., Shell, M., Henry, K. \& Maier, M. (2005) Achievement goals, performance contingencies, and performance attainment: an experimental test, Journal of Educational Psychology, 97 (4), 630-40.

Gibbs, G. (1992) Assessing More Students (Oxford, Oxford Brookes University).

Hammersley, M. (2001) On Michael Bassey's concept of the fuzzy generalisation, Oxford Review of Education, 27 (2), 219-225.

Harlen W, \& Deakin Crick R (2002) A systematic review of the impact of summative assessment and tests on learners' motivation for learning (EPPI-Centre Review), in: Research Evidence in Education Library. Issue 1. (London, EPPI-Centre, Social Science Research Unit, Institute of Education)

Harlen, W. \& Deakin Crick, R. (2003) Testing and motivation for learning, Assessment in Education, 10(2), 169-207.

Heckhausen, J. \& Farruggia, S. (2003) Developmental regulation across the life span: A controltheory approach and implications for secondary education. Development and Motivation, 2, 85102.

Hickey, D. \& McCaslin, M. (2001) A comparative, sociocultural analysis of context and motivation, in: S. Volet \& S. Järvelä (Eds.) Motivation in Learning Contexts (London, Pergamon), 33-55.

Hidi, S \& Harackiewicz, J. (2000) Motivating the academically unmotivated: a critical issue for the 21st century, Review of Educational Research, 70 (2), 151-179. 


\section{The significance of motivation in student-centred learning: a reflective case study}

Hogan, C. (1996). Getting the students to do the reading, think about it and share their ideas and responses, in: J.Abbott, \& L. Willcoxson, (Eds.) Teaching and Learning within and across Disciplines (Perth, Murdoch University), 79-81.

Hufton, N., Elliott, J. Illushin, L. (2002) Educational motivation and engagement: qualitative accounts from three countries, British Educational Research Journal, 28, 267-291.

James, M. \& Pedder, D. (2006) Professional learning as a condition for assessment for learning, in: J. Gardner (Ed.) Assessment and Learning (London, Sage), 27-43.

Krapp, A. \& Lewalter, D. (2001) Development of interests and interest-based motivational orientations: a longitudinal study in vocational school and work-settings, in: S. Volet \& S. Järvelä (Eds.) Motivation in Learning Contexts (London, Pergamon), 209-32.

Krapp, A. (2003) Interest and human development: an educational-psychological perspective, Development and Motivation, BJEP Monograph Series II, 2, 57-84.

Krapp, A. (2005) Basic needs and the development of interest and intrinsic motivational orientations, Learning and Instruction, 15, 381-395.

Leinhardt, G., McCarthy Young, K. \& Merriman, J. (1995) Integrating professional knowledge: the theory of practice and the practice of theory, Learning and Instruction, 5, 401-8.

Maclellan, E. \& Soden, R. (2004) The importance of epistemic cognition in student-centred learning, Instructional Science 32 (3) 253-268.

Mezulis, A., Abramson ,L., Hyde , J. \& Hankin , B. (2004) Is there a universal positivity bias in attributions? A meta-analytic review of individual, developmental, and cultural differences in the self-serving attributional bias, Psychological Bulletin, 130 (5), 711-47.

Mitchell, M. (1993) Situational interest: its multifaceted structure in the secondary school mathematics classroom, Journal of Educational Psychology, 85 (3), 424-36. 


\section{The significance of motivation in student-centred learning: a reflective case study}

Newman, R. (1994) Adaptive help seeking: a strategy of self-regulated learning, in: D. Schunk, \& B. Zimmerman (Eds.) Self-Regulation of Learning and Performance (Hillsdale, NJ:

Erlbaum), 283-301.

Newman, R. (1998) Students' help seeking during problem solving: influence of personal and contextual goals, Journal of Educational Psychology, 90 (4), 644-58.

Newman, R. (2002) What do I need to do to succeed? in: A. Wigfield \& J. Eccles (Eds.) Development of Achievement Motivation (London, Academic Press), 285-306.

Nisbet R. \& Wilson, T. (1977) Telling more than we can know: verbal reports on mental processes, Psychological Review, 84 (3), 231-259.

Oettingen, G., Hönig, G. \& Gollwitzer, P. (2000) Effective self-regulation of goal attainment, International Journal of Educational Research, 33, 705-32

Perrenoud, Ph. (1998) From formative evaluation to a controlled regulation of learning processes: towards a wider conceptual field, Assessment in Education, 5(1), 85-102.

Pintrich, P. (2003) Multiple goals and multiple pathways in the development of motivation and self-regulated learning, Development and Motivation, BJEP Monograph Series II, 2: 137-153.

Pintrich, P. \& Schunk, D. (2002) Motivation in Education (New Jersey, Prentice-Hall Merrill).

Soden, R. \& Maclellan, E. (2005) Helping education undergraduates to use appropriate criteria for evaluating accounts of motivation, Studies in Higher Education, 30 (4) 445-458.

Spinath, B, (2005) Development and modification of motivation and self-regulation in school contexts, Learning and Instruction, 15 (2), 85-86

Stake, R. (2003) Case Studies, in: N. Denzin \& Y. Lincoln (Eds.) Strategies of Qualitative Inquiry. (London, Sage Publications), 134-64. 


\section{The significance of motivation in student-centred learning: a reflective case study}

Struthers, C., Menec, V., Schonwetter, D.J. \& Perry, R. (1996) The effects of perceived attributions, action control, and creativity on college students' motivation and performance, Learning and Individual Differences, 8 (2) 121-39.

Struyven, K., Dochy, P. \& Janssens, S. (2003) Learners' perceptions about new modes of assessment, in: M. Segers, F. Dochy \& E. Cascallar (Eds.) Optimising New Modes of Assessment: in search of qualities and standards (London, Kluwer Academic Publishers), 171223.

Tesch, R. (1990) Qualitative Research: Analysis Types and Software Tools (London, Falmer Press).

Topping, K. (2003) Self and peer assessment in school and university, in: M.Segers, F. Dochy \& E. Cascallar (Eds.) Optimising New Modes of Assessment: in search of qualities and standards (London, Kluwer Academic Publishers), 55-87.

Torrance, H. \& Coultas, J. (2004) Do summative assessment and testing have a positive or negative effect on post-16 learners' motivation or learning in the learning and skills sector? $A$ Review of the Research Literature on Assessment in Post-Compulsory Education in the UK. London: Learning and Skills Development Agency.

Vermunt, J. \& Verloop N. (1999) Congruence and friction between learning and teaching, Learning and Instruction, 9, 257-80.

Weiner, B. (1979). A theory of motivation for some classroom experiences, Journal of Educational Psychology, 71, 3-25.

Weiner, B. (1985). An attributional theory of achievement motivation and emotion, Psychological Review, 92, 548-573.

Winter, R. (1989) Learning from Experience: Principles and Practice in Action-Research. (Lewes, Falmer). 


\section{The significance of motivation in student-centred learning: a reflective case study}

Wosnitza, M. \& Nenniger P. (2001) Perceived learning environments and the individual learning process, in: S. Volet \& S. Järvelä (Eds.) Motivation in Learning Contexts (London, Pergamon), 171-87.

Appendix: A Selection of Recording Units for Each Episode $(M=$ minority view; $\mathrm{T}=$ typical view)

\section{$\underline{\text { Task Determination }}$}

I want to know what the learning outcomes are but I'm up for suggesting what some of the content might be. (M)

I like the opportunity to discuss my understanding with peers but this should not be the only learning experience in tutorials. (M)

I can't see why I should have to read difficult journal articles. The lectures should provide me with all I need to know (T)

It's the tutor's job to organise the tutorial. (T)

I want to know, clearly, what the tutor expects. (T)

$\underline{\text { Task Continuation }}$

The lead tutor draws attention to particular issues in practice and then highlights the articles we should read. In that way I learn about the issue myself. (M)

The tutor doesn't give all the information but provides questions and prompts to get you to make your own notes. (M)

There's too much to read and while it's informative it's also confusing. I don't know who to believe. (T)

I do only the minimum amount because I can't see what good the module is doing me. (T)

The tutor needs to explain the readings well. (T)

Why doesn't she just tell us what we should believe? (T)

A closer connection between content of the lecture and content of the tutorial is needed. (T)

\section{$\underline{\text { Task Completion }}$}

All the stuff about Behaviourism and Constructivism that I now know helps me to make sense of stuff we did in the last two years. (M)

We spent ages on the study tasks. They're great for getting us to exchange ideas, share information and be clear where we stand. That's what the assessment task was about. (M) I read all the material and knew the stuff but I didn't pass the assessment. (T) Assignment covers too many things and only 2,000 words to write it. (T) Everything I learned came from lectures, not the study tasks or the reading. (T) 